\title{
The Current Situation of Myanmar Migrants in Thai Economy: Social Integration Case of Samut Sakhon Province, Thailand
}

\author{
Yingsak Vanpetch, Mahachai Sattayathamrongthian
}

\begin{abstract}
This research aims to examine the current situation of the Thai community due to the inflow of Migrant worker in Samut Sakhon in 2019 by applying qualitative method. The sampling group consists of twenty-five business owners in Samut Sakhon province; that is mostly small businesses and medium enterprises with between 20 and 50 employees, have been operating the business more than ten years in operating and currently is hiring Myanmar workers. Data were collected through in-depth interviews and secondary resources. The research found: there is no significant change in labor turnover. Government's rules and regulations rarely have a practical effect on Myanmar workers; besides, most areas are not controlled by the authorities. Myanmar communities in Thailand grow due to the increasing number of Myanmar workers. Some of the Myanmar workers establish their businesses that serve the community in the area. Myanmar workers became a part of the industry in the Samut Sakhon province. Both Myanmar workers and Thai business owners have to adapt according to the situation of economic and social changes. Myanmar workers are also satisfied with the compensation. Meanwhile, most of Thai business owners prefer to hire laborers from Myanmar now and in the foreseeable future.
\end{abstract}

Keyword: Labour migration, Myanmar workers, Samut Sakhon, Thailand.

\section{INTRODUCTION}

Most migrant workers in Samut Sakhon province are from Myanmar who hopes and dream of making enough money to support their families back home; feed themselves; purchase land and home; and - like many immigrants who came before them - at last, return to their homeland.In 2018, the official number of migrant workers was 3.08 million people (Ministry of Labour, 2018).Most of the small and medium Thai businesses enjoy the benefits from the inflow of these migrant workers in terms of production cost reduction. Foreign migrant workers coming to Thailand are lack of bargaining power and are usually willing to accept lower wages (Saksiriruthai, 2015). According to the previous study on the employers' willingness to pay of Myanmar migrant workers in order to work in Thailand, the migrant workers' perception of working legally and illegally in Thailand are not significantly different

(Panjatewacoop,

Sattayathamrongthian, 2014).

Revised Version Manuscript Received on 16 September, 2019.

* Correspondence Author

Yingsak Vanpetch, International College,Suan Sunandha Rajabhat University, Nakhon Pathom, Thailand e-mail:yingsak.va@ssru.ac.th

Mahachai Sattayathamrongthian, Rajamangala University of Technology Rattanakosin, Nakhon Pathom, Thailand. e-mail: mahachai.sat@rmutr.ac.th

\section{RESEARCH OBJECTIVE}

To examine the current situation of the Thai community due to the inflow of Migrant workers in Samut Sakhon, Thailand.

\section{Literature REVIEW}

In its most broad sense "migration" is typically characterized as the moderately constant development of people over a considerable separation. However, this definition, or any summarization of it, starts to delimit the subject, for the correct significance of the most important terms ("permanent," "significant") is still to be determined.

Push and pull factors

Push factors that have an impact on immigration patterns vary from country to country, but the majority reasons are to improve the standard of living, to search of work and income to support their families back home. Myanmar workers migrate to Thailand, often due to economic opportunity, the wage differential, and, for married couples, to accompany their spouses (Fujita et al. 2010, Ushakov et al, 2018).

Pull factors are the business elements within Thailand, which include the ongoing demand for a low-cost, unskilled labor force to fill jobs no longer attractive to Thai citizens due to low pay, limited or no benefits and substandard work conditions .Besides, the wages in Thailand are higher than what these unskilled migrant workers can find in Myanmar.The legal minimum wage in Myanmar is 4,800 kyat (US\$3.00) (Overeem, 2018).

The Thailand minimum daily wage increased from 300 Thai Baht (THB) per day to 325 (US\$10.00) THB per day in 2018 (Chicarelli, 2018) has also attracted more influx of migrant workers. Other more direct pull factors have included the memorandum of understanding (MOU) in regarding recruitment of workers from Myanmar to work in Thailand. Particular literature, Transformation of The Communities as Resulted by Low-Skill Immigrants, offers a revealing look at how a group of people bound geographically, culturally, linguistically and economically during hostile times has flourished to become a vibrant, courageous community in Samut Sakhon province in Thailand.

As a result of the influx of low skill immigrants, the communities are found to be transformed similarly. The transformations originated from the arrival of the immigrants in search of opportunities to improve their

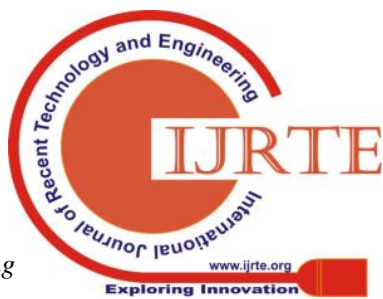


quality of life. These immigrants would reside within the area that their low income can afford, which are typically the area with low cost of living, but with tremendous employment opportunities (Nita, 2000; David, 2007). The increase in such low-skill immigrant population would often result in deterioration of the communities.

Immigrant tend to cluster in close geographic areas and develop networks, community relations, and interpersonal relationships through which they can exchange support, excellent, services, and trade with each other. This behavior leads to the growth of population with immigrants from the similar ethnic and cultural background and the birth of immigrant communities.

Such communities would become a geographic residential or industrial area with high ethnic concentration, characteristic, and cultural identity (Ushakov, 2016). Such communities are referred to as ethnic enclaves. As the ethnic enclave grows, so is the number of business establishments that bring in goods and services to satisfy the demand of the people there. An excellent example of such establishments is restaurants, grocery stores, etc. as evidenced by the billboards and advertisements posted in languages of the dominant ethnic group in the nearby area (Tsui, 2011).

The area where the migrant community is located is often more deteriorated than the typical standard. It is often likely that the original population in the neighborhood would choose to relocate to other areas that are not deteriorating due to the increasing immigrant population. The good and services in the area are often tailored to for the growing population of the migrant consumers. Such communities with a foreign migrant population often organize religious activities or establish religion shrines in the same manner that can be seen in China Town such as Ghost Spirit Gates, etc.

Increased supply of low skilled immigrants raises concerns about the economic opportunities of the least skilled natives. As the supply of low-wage workers increases, wages for native workers seeking similar employment decrease. While native employees lose from lower wages, employers benefit from lower costs. These lower costs can lead to a decrease in the cost of the good for native consumers (i.e. cheaper goods and services), which may result in an increase of gain to native-owned firms. Ethnic enclaves expand the size of the market, encouraging cross-cultural interactions, and introducing American to a variety of different products and cuisines (Borjas, 1999).

Verifiably, the arrangement of ethnic enclaves has been the consequence of an assortment of financial elements that attract outsiders to comparable spaces in the getting nation. The absence of access to financial capital and learning with respect to private neighborhoods can oblige recently arrived foreigners to areas of reasonable lodging. Common elements, for example, preference and bigotry, may move co-ethnics into areas showing ethnic similitude. Lodging separation may likewise keep ethnic minorities from subsiding into a specific neighborhood outside the enclave.

When talking about the ethnic enclave as characterized by a spatial group of organizations, achievement and development can be to a great extent anticipated by three elements. These variables incorporate the size and populace of the enclave, the degree of enterprising abilities of those in the enclave, and the accessibility of capital assets to the enclave. Fruitful enclaves can arrive at a point where they become independent, or "institutionally complete" through

the supply of new outsiders and request of products offered in the market. They arrive at this point after first providing for the necessities of co-ethnics and afterward growing to address the issues of those in the bigger market of the host society

\section{METHODOLOGY}

After the literature review and conceptualization of the research structure, the researchers have decided to employ the qualitative research methods to obtain data from twenty-five business owners in Samut Sakhon province; which are mostly small businesses and medium enterprises with between 20 and 50 employees, have been operating business more than ten years and currently is hiring Myanmar workers for their business operations. Data was collected through in-depth interviews and secondary resources.

A typical interview is more than merely asking questions and receiving responses; the goal is to create a safe and open dialogue whereby the participant may authentically discuss his or her experiences or meanings.

The interview topics are:

1. The current situation of the Myanmar migrant worker's communities

2. The current problems with hiring the migrant worker, the attitude towards problems and guideline

The breakdown of the participants is as follow:

Table 1 - Research participants: 25 Total

\begin{tabular}{|l|c|c|}
\hline \multicolumn{2}{|c|}{ Demographic } \\
\hline Gender: & Male & 15 \\
& Female & 10 \\
& & \\
\hline Age: & $15-30$ & 1 \\
& $31-45$ & 7 \\
& $46-60$ & 11 \\
Educational & 61 and over & 6 \\
Background: & Lower than Bachelor & 15 \\
& Bachelor Degree & 8 \\
& Higher than the bachelor & 2 \\
& degree & \\
\hline
\end{tabular}

Table 2 - Business Information

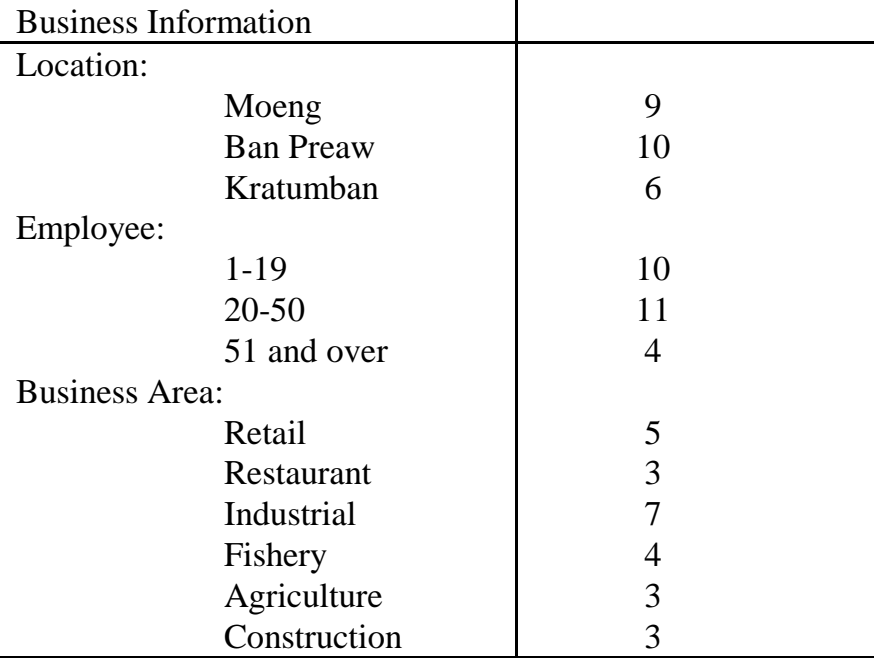




\section{RESEARCH RESULT}

The situation of Myanmar migrant workers during late 2018 to early 2019 has changed in many aspects, such as worker's living arrangement, business owner's opinion toward the workers, and how the communities in the area adapt to the on-going change of the situation.

\section{The living arrangements of the migrant workers}

The living arrangements of the migrant workers within the Samut Sakhon province area can be summarized into three different categories:

1. Most of the immigrants stay at the factory or the places arranged by the employer, or nearby the work location. There are several business entities in Samut Sakhon province that make such arrangement for migrant workers who are under their employment. The arrangement includes low-cost living space, which can be deducted directly from the wages earned by the workers.

2. The apartment complex and low-cost rental housing are in the area near the location of the businesses. There is currently much rental housing that caters to the migrant workers within the Samut Sakhon area. A typical worker housing and apartment rental rate range from 600 Thai Baht (THB) per month to 4,000 THB per month. The communities with many housings for migrant workers have been experiencing the boom of other business opportunities that provides products and services and other necessity for the migrant workers staying in the communities.

3. A house belongs to the spouses of the migrant workers, in the case that the Myanmar migrant worker is married to a Thai spouse who resides in Samut Sakhon or nearby area.

\section{The migrant worker's communities are increasing}

The emergence and expansion of Myanmar communities make way for Myanmar business owners in the area. Samut Sakhon province is experiencing the growth of the migrant worker's communities with the second category of living arrangement, due to a large number of Myanmar migrant workers in the area. Following the growth of the workers' apartment buildings, is the growth of small businesses providing necessities and commodities for the workers, such as money transferring services, Myanmar food and merchandise stores, and immigration paper processing companies.

In the past, these businesses are owned and operated by Thai business owners. However, recently many of these businesses are owned and operated by people from Myanmar, which is against Thai labor laws, which prohibits alien laborer, including Myanmar migrant workers, to perform any other works other than labor works (Ministry of Labour, 2016). The business operations conducted by Myanmar migrants are much more lucrative than doing labor works, which in turns, attracts more Myanmar workers to become interested in starting their own business in Thailand.

The benefit of increasing of Myanmar Communities in Samut Sakhon
1. Recruitment and supplying of Myanmar migrant labors for business are common and done in two different methods. One method is done by word of mouth within the Myanmar worker communities.The employer would ask workers currently under his or her employment for the recommendation for a good worker. The workers would recommend anyone already in the region. Since traveling into Thailand can be done quickly, sometime the worker would invite their relatives from Myanmar to migrant into Thailand to fill the first position. Most entrepreneurs do not like using a staffing agency to supply them with the workers since the cost incurred by the agencies are generally high, ranging from 8,000 THB to 15,000 THB and often without any guarantee of the quality of the workers being provided for such high fee. One entrepreneur from Ban Praew District disclosed that he does not favor using the staffing agencies because he feels he was cheated by such agency before. He further disclosed that a decade ago, a staffing agency supplied him with Myanmar migrant workers for a staffing fee of 4,000 Baht. The worker left his work only two days after, leaving him without helping hand and no way to file any claim against the agency. He later found that the whole incident was the arrangement between the agency and the worker.

2. The businesses that benefit from Myanmar communities are the business related to supporting the supplying of the Myanmar migrant workforce such businesses are the immigration and work permit processing companies, transportation companies that provide mean of transports from Samut Sakhon to Thai-Myanmar border. Myanmar immigrants may obtain visas and registration documents from one of these organizations without having any official documentation on them. The cost for the documentation processing ranges from $20,000 \mathrm{THB}$ to $25,000 \mathrm{THB}$. The average transportation expense from Samut Sakhorn to the Thai-Myanmar border in Kanchanaburi is approximately 2,500 THB. Most entrepreneurs believe that the Myanmar migrant workers situation has not changed much from the recent past, the hiring process, and the nature of working with these workers.

\section{The negative cause of increasing of Myanmar} Communities in Samut Sakhon

1. Some communities become congested. The deterioration of the communities harms Thai people in the area. Some of them have decided to move out of the area. The increase of Myanmar workers' population also impacts the local government agencies because they have to stretch their resources harder to provide necessary services such as public safety and health care.

2. The phenomenon harms the population in the region, more specifically, the small business and medium enterprises owned by Thai business persons. It also appears that Myanmar business owners can meet Myanmar consumers demand more effectively than Thai businesses. Thus, Thai businesses such as restaurants and convenience stores are experiencing increasing competition from emerging Myanmar businesses and earning less income as a result. However, the large businesses are experiencing minimal impact from the growing small Myanmar businesses. This is because the big companies, such as big property 
management companies, wireless telephone service providers, and import/export companies, have more resources at their disposal and are also gaining benefits from the emergence of the Myanmar businesses.

3. The current economic situation has some negative impacts on most business owners, but not very severe to the point where they need to lay off workers. Thus, the economy has no significant direct impact on Myanmar workers. Most business owners expressed that if they need to hire more workforce, they will be willing to hire more Myanmar workers again.

Myanmar migrant workers may travel back and forth from Thailand to Myanmar to visit their family they left behind. Business owners expressed that according to their workers, most of Myanmar countryside, where most workers reside, are still underdeveloped. Thus, most Myanmar workers still would like to stay and work in Thailand and enjoy the prosperity that their homeland lacks.

\section{Recommendations on migrant management for preparation}

In the study of Myanmar labor centers in Nakhon Pathom province: problems and living Together in the community, the researcher has suggested guiding the management of migrant workers. In preparation for dealing with Nakhon Pathom to be a livable community as follows:

1 The Thai government should focus on establish policies and management of migrant workers. Besides, Thai people in the community that lives together with migrant workers should reduce negative prejudice against migrant workers

2 Local government agencies and national governments should turn to the area and listen to community problems in the area where co-workers are living with migrant workers That should pay attention and come to manage seriously is the public health problems regarding control of diseases and epidemics, deteriorating and dirty environment problems and crime since the said problem is the root cause of resentment of people in the area to migrant workers. Eliminating such problems will help reduce the level of satisfied between two groups of people can lead to conflict

3 Samut Sakhon Province government agencies should cooperate with entrepreneurs, employers, and landlords to improve the quality of life of workers. This is due to the impact on all aspects of most caused by neglect to deal with the root cause of this problem.

4 Entrepreneurs, factories, shops, service places, employers in agriculture and other sectors that employ migrant workers should be aware of regulations and choose to hire workers to enter the country legally for the benefit of the Government sector in the management of migrant workers and to enable migrant workers to access to various services and benefits that are desirable. Besides, the hiring of the right labor laws when problems arise, such as the occurrence of various criminal cases with migrant workers.

Finally, employers who hire migrant workers should firmly in respect for human rights and human security is the key.

5. The Thai state must move away from the traditional management of migrant workers. Consider the issue of children of migrant workers and education, which are labor followers. Multinational in Thailand including children of migrant workers born in Thailand and more marriages between Thais and migrant workers because of this will become a challenge to the determination of labor possibilities and communities in Samut Sakhon Province and the national level in the future.

\section{CONClusion}

The current situation of the Myanmar communities has provided opportunities for the Myanmar workers who traveled to work in Thailand illegally to be able to live in Thailand more comfortably. The phenomenon where the illegal inflow of Myanmar workers into Samut Sakhon and the hiring of illegal Myanmar workers in the region will continue to exist until the standard of living in Myanmar catch up or exceed Thailand.

The Myanmar immigrants are willing to travel into Thailand legally or illegally, relatively distribute benefits to the Thai business, the workers themselves, and the related a particular group of people.

\section{ACKNOWLEDGMENT}

The authors would like to thank Suan Sunandha Rajabhat University and Rajamangala University of Technology Rattanakosin for all of the supports.

\section{REFERENCES}

1. Abrahamson, M. (1995). Urban Enclaves: Identity and Place in America. New York: St. Martin's Press

2. Bodvarsson, O. B., \& Berg, H.V. ( 2009). The Economics of Immigration: Theory and Policy. New York, NY: Springer.

3. Borjas, Ge. J. (1999). Heaven's Door: Immigration Policy and the American Economy. Princeton: Princeton University Press. 8-11

4. Chantavanich, S. ( 2012). Policy Review on Myanmar Economy: Myanmar Migrants to Thailand and Implications to Myanmar Development, Bangkok Research Center, JETRO Bangkok

5. Chicarelli Marisa (2018) New Minimum Wage Rates in Force in Thailand

https://gps-legalconsulting.com/publications/new-minimum-wage-rat es-in-force-in-thailand/

6. Daugherty H. G., Kammeyer K. W. (1995). An introduction to population. New York: Guilford Press

7. Fujita, K., Endo, T., Okamoto, I., Nakanishi, Y., \& Yamada, M. (2010). Myanmar migrant laborers in Ranong, Thailand. IDE Discussion Paper No. 257, Institute for Developing Economies.

8. Hummon, D. M. ( 1996). Contemporary Sociology. American Sociological Association. Vol. 25 No. 6. 781-782.

9. Lelyveld, N. (2000). In Los Angeles, the Newest Ethnic Enclave: Thai Town. Los Angeles Times, Philadelphia Inquirer, A-21

10. Ministry of labor (2018) Office of Foreign Workers Administration, Department of Employment, Ministry of Labor, Thailand

11. Pauline Overeem (2018) Higher minimum wage in Myanmar: bad news for workers? https://www.somo.n1/higher-minimum-wage-in-myanmar-bad-news-f or-workers/

12. Panjatewacoop, P., Sattayathamrongthian, M. (2014). Willingness to pay for Thailand's Foreign Workers, Case Study of Myanmar Workers in Samut Songkram Province, http://www.econ.tu.ac.th/oldweb/doc/content/1299/Discussion_Paper No.32.pdf 
13. Pierson, D., \& Gorman, A. (2007, August 2). A new take on Thai Town Capitalizing on the area's unique ethnic mix, community leaders draw plans to revitalize the diverse neighborhood. Los Angeles Times. Retrieved http://articles.latimes.com/2007/aug/02/local/me-thaitown2

14. Portes, A. (1995). Chapter 1: Economic Sociology and the Sociology of Immigration: A conceptual Overview, In Portes, Alejandro. The Economic Sociology of Immigration. Russel Sage Foundation. 1-41.

15. Saksiriruthai, S.(2015).Urbanization and Migration as Factors Affecting Global Economic Development.Suan Sunandha Rajabhat University, Thailand, DOI: 10.4018-978-1-4666-7328-1.ch004

16. Theingi, H., \& Mon, M. (2010). The potential contribution of return migrants in Burma's trade and investment liberalization strategy. 18th Biennial Conference of the Asian Studies Association of Australia, Adelaide, Australia.

17. Todaro, M. P., \& Smith, S. C. (2006). Economic development. Harlow: Addison-Wesley.

18. Ushakov, D. (2015). Labor immigration in dynamics of European Union's national economic progress: macroeconomic analysis and basic indicators. Actual Problems of Economics, 3.

19. Ushakov, D., Rubinskaya, E. (2018). Reforming of the state immigration policy in the context of globalization: On the example of Russia. In: Immigration and the Current Social, Political, and Economic Climate: Breakthroughs in Research and Practice. IGI-global. 